\title{
ANTICLERICALISMO, REGIONALISMOY MOVILIZACIÓN SOCIAL. EL MOTÍN ANTIARZOBISPAL DE COPIAPÓ EN 1853
}

\author{
ANTICLERICALISM, REGIONALISM AND SOCIAL \\ MOBILIZATION. THE ANTIARZOBISPAL RIOT IN COPIAPÓ 1853
}

Joaquín Fernández Abara *

\begin{abstract}
RESUMEN
El 25 de diciembre de 1853, en Copiapó, una muchedumbre quemó un edicto del Arzobispo de Santiago que llamaba a denunciar a los "sospechosos de herejia". En este articulo queremos mostrar como estos hechos dejaron a la vista la manera en que regionalismo y anticlericalismo iban de la mano en Copiapó, unidos por un discurso modernizador que menospreciaba el tradicionalismo del Chile central y resentia el peso excesivo de la capital. También queremos dar cuenta de las formas que adquiria el anticlericalismo copiapino, recalcando como la libertad de conciencia fue ensalzada como valor supremo y las autoridades religiosas llegaton a verse despojadas de respeto a su investidura y de su sacralidad. Pretendemos conocer los diversos grupos sociales que tomaron parte en esta manifestación y los dilemas que generó la posible participación de turbas de peones mineros en estos sucesos. También analizaremos las posturas de los diversos grupos políticos en torno a esta polémica, demostrando cómo las posiciones asumidas por liberales y conservadores no eran antirreligiosas, pero si demostraban distintos grados de anticlericalismo. Los liberales cuestionaban la idea de religión institucionalizada, y la sustifuian por una esperanza utópica de retorno al cristianismo primitivo, una iglesia ajena al poder y unida por las ideas de caridad y fraternidad universal. Los sectores gobiernistas apuntaron sus reclamos a someter al clero al poder civil, en posturas de un talante mis bien regalista.
\end{abstract}

Palabras Clave: Regionalismo, Anticiericalismo, Movilización Social, Copiapó, Siglo XIX.

\section{ABSTRACT}

On december 25 of the year 1853 , in Copiapó, a multitude burned an edict of the archbishop of Santiago. The ediet called to report the residents "suspicious" of being "heretics". On this paper 1 want to show that those events proved bow regionalism and anticlericalism were united in Copiapo, linked by a pro-modernization discourse that despised the traditionalism of the Chilean Central Valley and refised the excessive concentration of power in the capital city 1 also want to show the forms that Copiapo's anticlericalism acquired emphasizing on how the freedom of conscience was elevated as the supreme value, and how the religious authorities were deprived of the respect to their investiture and were desacralizated. We pretend to know the different social groups that tacked part in this demonstration and the questions that were created in view of the possible participation of a mob of miner laborers. I will also analyze the positions adopted by different political groups before this discussion, showing how the stances of liberals and conservatives were not antireligious, but expressed different levels of anticlericalism. The liberals questioned the idea of irstitutional religion, replacing it by an utopic hope of retum to primitive cristianism, a Catholic Church distanced of power and united by the ideals of charity and universal fraternity. On the other side, political groups identified with the government urged to submit the clergy to the civil authorities, defending regalist ideas

Key Words: Regionalism, Anticlericalism, Social Mobilization, Copiapó, $19^{\text {th }}$ Century.

\section{INTRODUCCIÓN}

Uno de los campos de estudio más interesantes sobre el desarrollo del regionalismo en Chile, a mediados del Siglo XIX, es el caso de Copiapó. Ciudad ubicada en el entonces extremo norte del país, que se benefíció enormemente del boom minero producido por el descubrimiento de yacimientos argentíferos en la década de 1830. Diversos autores, entre otros Maurice Zeitlin, han llegado a calificar a dicha ciudad como una suerte de segundo centro de soberanía política, debido al poder económico alcanzado por ciertas familias

\footnotetext{
- Universidad Alberto Hurtado, Pontificia Universidad Catolica de Chile.
} 
locales gracias a la mineria. Las caracteristicas distintivas de la sociedad copiapina, una especie de "sociedad de frontera", con un carácter más abierto y democrático, de barreras de clase menos rigidas, habrian permitido el surgimiento de una conciencia democrática bastante radical para su tiempo, la que habria permeado a las élites locales, contraponiéndolas a los grupos dirigentes del núcleo central chileno!

Copiapó, capital de la provincia de Atacama, fue la zona que en 1859 lideró las fuerzas antigobiernistas en la llamada Revolución Constituyente, que pretendia cambiar el orden politico del pais, llamando a reformar la constitución y a contener el poder del Ejecutivo. En Copiapó, los llamados a la "lucha contra el centralismo" y a resistir la "invasión centralizadora del ejecutivo" estuvieron a la orden del dia durante la revolución y el periodo que la precedió, transformando al autonomismo regional en uno de sus principales motivos ${ }^{2}$. Tras la guerra civil de 1859, los dirigentes derrotados que retornaron a Copiapó formaron en la década de 1860 las primeras asambleas radicales, las que derivaron en la formación del Partido Radical, polo laicista del espectro político chileno por más de medio siglo ${ }^{3}$. La transición de estas élites hacia el radicalismo político, el regionalismo y el papel que tuvo en esta transformación el anticlericalismo se vuelven interesantes temas de estudio. Ello debido, en parte, a que en los comienzos de la década de 1850, estas mismas élites copiapinas se encontraban en buenas relaciones con el orden conservador imperante en Santiago. El grueso de ellas habia dado su concurso a la candidatura presidencial de Manuel Montt, y durante la guerra civil de 1851 prestaron su apoyo a las fuerzas Gobiernistas en contra de los levantamientos liberales y de los conatos de insurreceión realizados por peones mineros y obreros carrilanos en la zona ${ }^{4}$.

A fines del año 1853 ya podian observarse algunas fracturas en esta convivencia: Las élites locales, a través de su órgano de prensa El Copiapino, se quejaban de la falta de atención đel gobierno central, a la vez que alegaban sobre cómo los intendentes y, en general, todo el aparato del ejecutivo, violentaba la autonomia loçal y entorpecia los intentos de gestión administrativa de los vecinos 5 .

Los sectores más clericales del conservadurismo eran mirados con cautela por las élites mineras copiapinas, que no aprobaban su participación en los gabinetes y que resentian sus intentos cada vez más activos de reintroducir a la orden jesuita en Chile ${ }^{6}$. Estos intentos se concretaron legalmente en 1854, pese a las objeciones del propio Presidente, y dejaron en evidencia los primeros sintomas de ruptura en el tronco conservador, entre los sectores ultramontanos y los proclives al patronato, ruptura que estallaría sólo un par de años más tarde ${ }^{7}$.

Fue en este contexto que importantes sectores de las élites copiapinas, apoyados por la oposición liberal, realizaron un inédito acto de protesta contra un edicto del arzobispo de Santiago.

\section{REGIONALISMO Y ANTICLERICALISMO}

El dia 20 de diciembre de 1853 vio la luz un articulo en la primera plana del periódico El Copiapino. titulado "Pastoral del arzobispo de Santiago". Este artículo cuestionaba un Edicto eclesiástico destinado a preparar la visita del arzobispo a su diócesis. El articulo partia reproduciendo un extracto del Edicto como epigrafe:

"A todos universalmente ordenamos, bajo pena de nuestro arbitrio, a más de las que dispone el derecho, que hagan ante nos, o ante nuestros convisitadores, la denuncia de los que por hecho o palabra sean sospechosos de herejia, excomulgados, o que de alguna manera perviertan las

\footnotetext{
- Agradecemos los comentarios det profesor Roberto Di Stefano

1 Zeitlin, Maurice, The civil wars in Chile (Or the buergeosis revolations that never were), Princeton, Princeton University Prese, 1984 ". pp. 21 .70 y Gazmuri, Cristian, El "48" Chileno. Igaalitarios, reformistas, nadicales, masnenes y bemberos, Santiago, Fditorial Universitaria, 1998, pp, I30-131.

2 Estas frases y tógicos fueron reiterados por diversas fuentes que nos han legado los revolucionarios, podemos encontrarlas en algunos numeros del periódico opositor El Norte, editado en Copiapó en 1858. Véase también la monumental obra de Figueroa, Pedro Pablo, 1889 Historia de la Revohíción Constifugente (1858-1859), Escrita sobre documentos completamente indiditos, Santiaga Imprenta Victoria, de H. tzquierdo y Cia, Pp. 221 -458.

3. Gazmuri, Cristian, EI "48"...loc, Cit.

4 Mlanes, Maria Angébica 2003. "Proyecto comunal y guerra civil. $1810-1891$ ", en Mlanes, Maria Angética, Chile Des-centrada Formación sociocultural

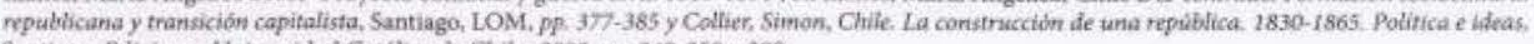
Santiago, Ediciones Universidad Catolica de Chile, 2005, pp, 249-250 y 288.

3. Diversos reclamos sobre estos asuntos están tegistrados en El Copiapino a lo largo de 1853 y 1854.

6. TVapor del Sud. Chile. Correspondencia para el extranjero, en Eil Copiapino, Copiapó, 20 de diciembre de 1853.

7 Scully, Timothy R. 1992, Las partidos de centro y la ewolución politica chilena, Santiago, CIFPL_AN-Notre Dame, p, 52
}

Revista de Historia, ano 18, vols. 18-19, 2008-2009, pp. 197-211. 
costumbres; exhortando y rogando en el Señor a todo aquel que tuviere que comunicarnos cualquier asunto, se desnude de toda pasión y mire en lo que hace únicamente a la Gloria del Señor" ${ }^{\prime \prime}$.

El articulo cuestionaba este trozo del edicto arzobispal, y lo acusaba de estar basado en preceptos de carácter "odioso, inmoral y retrógrado" y de fomentar la "discordia religiosa entre conocidos, entre padres e hijos, entre marido y mujer", sembrando "la semilla de la discordia en el seno de inocentes familias". También sostenia que alejaba la inmigración extranjera, degradando la imagen de Chile en el exterior y afectando los proyectos existentes en este sentido. Finalmente, protestaba que el edicto pisoteaba la "carta fundamental, que promete no molestar a nadie por sus opiniones religiosas"9. Como vemos, se trata de una defensa de la "libertad de conciencia", del respeto a la intimidad de la vida privada, de la cohesión de la comunidad local y del proyecto civilizador del país por medio de la inmigración extranjera.

Esta fuerte reacción puede ser explicada como una defensa de los derechos de los inmigrantes protestantes residentes en Copiapó. No tenemos noticias de chilenos nativos convertidos al protestantismo en la zona hacia el año 1854 , y las fuentes consultadas tienden a sindicar como protestantes exclusivamente a extranjeros residentes.

La pujante actividad minera habia transformado a esta ciudad en un imán para la inmigración, especialmente masculina. Sin embargo, el grueso de los inmigrantes no era protestante, de hecho predominaban los de de origen argentino, que bordeaban los 5.000. La provincia entera de Atacama tenía 50.690 habitantes, de los cuales más de un $60 \%$ se concentraban en el departamento de Copiapó. De éstos, apenas 683 provenian de zonas del mundo con fuerte presencia protestante, dato que debemos tener en cuenta, pues en el censo de 1854 no se hacian preguntas sobre religión a los encuestados.

Como vemos, la población protestante representaba una pequeña proporción de la población. Sin embargo, testimonios de la época muestran cómo alcanzaron importantes posiciones en el comercio, la actividad minera y los servicios asociados a ella, mezclándose y alcanzando buenas relaciones con la élite local.

\section{Inmigrantes de zonas con fuerte presencia protestante residentes en la provincia de Atacama en $1854^{10}$}

\begin{tabular}{|l|r|}
\hline Estados Unidos & 72 \\
\hline Canadá & 1 \\
\hline Suiza & 2 \\
\hline Alemania & 110 \\
\hline Holanda & 1 \\
\hline Prusia & 4 \\
\hline Dinamarca & 7 \\
\hline Inglaterra & 472 \\
\hline Escocia & 13 \\
\hline Noruega & 1 \\
\hline TOTAL & 683 \\
\hline
\end{tabular}

Bajo esta óptica, la protesta contra el edicto puede ser analizada como parte de la lucha por la tolerancia hacia los protestantes y por el debilitamiento de la influencia de la lglesia. Esta ha sido la óptica con que la historiografia liberal ha tendido a mirar las pugnas laico-clericales en el siglo XIX ${ }^{11}$.

Sin embargo, el análisis de los modos y leguajes que adquirió la protesta puede llevarnos a entender conflictos más ricos y complejos que subyacian tras ésta, evitando la construcción de visiones homogèneas y lineales sobre la secularización chilena en el siglo XIX y analizando las formas que tomó el anticlericalismo. Debemos poner atención a que el texto no se detenia exclusivamente en la defensa de los ya mencionados

\footnotetext{
"Pastoral del Arzobispo de Santiago", en Ei Copiapino, Copiapó, 20 de diciembre de I853,

- Did.

10. Los datos estin tomados del Censo feneral de la Repuiblica de Chile, Levantado en abril de 1854, Santiaga, Imprenta del Ferrocarril, 1854.

11 Una muestra clasica de este tipo de historiografia es la obra de Donosa Ricando, Las ideas politicas en Chile, Mexico D.F. Fondo de Caltura Fcondimica, 1946, pp. 174-326.
} 
principios, pues estaba salpicado de duros ataques al alto clero santiaguino. expresados en invectivas de un marcado tinte anticlerical: Acusaba al arzobispo de "encender las llamas inquisitoriales en pleno siglo XIX" y querer "volver a los dichosos tiempos de los Torquemadas". A la vez, sostenia que el edieto era obra del "sanedrin farisaico que rodea al jefe espiritual de Santiago", el que a juicio de los redactores de El Copiapino seria "una especie de logia jesuitica, en la que bajo el más estricto sigilo se disponen de los empleos y dignidades de la Iglesia, se extienden las redes ocuitas de los influjos, y se pretende enfrenar aun el poder supremo". Queda claro como el antijesuitismo y el antiinquisitorialismo, motivos clásicos del anticlericalismo, se hacian presentes, advirtiendo a los lectores, por un lado, sobre los peligros que encerrarian el fanatismo y las persecuciones religiosas $y$, por el otro, sobre las redes de poder asociadas a las órdenes religiosas, las que minarian el poder de la autoridad civil. Los ataques a la relajación e inmoralidad del clero se hacian presentes en el articulo, pues este sostenia que en vez de desatar persecuciones, el clero deberia dedicarse a "corregir la relajación de costumbres de tantos curas dedicados a henchir sus bolsillos con las lágrimas de sus infelices feligreses ${ }^{* 12}$

El alegato anticlerical estaba cargado de un fuerte sentimiento regionalista. De hecho, comenzaba diciendo que "otras veces hemos dicho que de nuestra vieja capital no nos vienen sino miserias; pero la que nos ha traido el último vapor ha sido tan grande que nos ha espantado". Lnego contraponía la imagen del "libre suelo" de Copiapó al "atraso" de Santiago y el Chile rural:

"Bien lo conocen los actuales fariseos con dirigirse hacia los campos del sur, cuya civilización está atrasada por lo menos de un siglo. Alli pueden campear a su gusto, y llenarse de chismes, sin cuya atmósfera no pueden respirar estos miserables insectos $(\ldots)$ tambièn podrian dedicarse a purificar nuestra santa capital vieja y arrugada que no podria limpiarse ni con toda la lejía de la República. Oh! Alli si que se necesitaria fuego expurgatorio, pero para tanto hipocritón que de día se golpea los pechos en las iglesias para ganarse la confianza de los devotos sencillos, y después saquearlos a su gusto, para ser nombrados síndicos de conventos y albaceas de ricas beatas. Estos lobos vestidos con piel de oveja debian ser quemados públicamente en la plaza de Santiago"13.

Como puede inferirse del análisis del artículo de El Copiapino, en los alegatos contra el edicto se fundían elementos anticlericales y regionalistas. Los redactores de El Copiapino pretendian contraponer la imagen de un Copiapó tolerante, abierto a la inmigración extranjera, moderno y civilizado, a la de un Santiago y un Chile rural atrasados e intolerantes. El sentimiento regionalista se sentia herido por un edicto, impuesto desde Santiago, que mandaria a fomentar la delación, debilitando los lazos de cohesión de la comunidad local. La reacción anticlerical no apuntaba en contra de la religión en si misma, sino a la intolerancia; la falta de respeto a la libertad de conciencia; al atropello al poder civil, especialmente de parte de órdenes religiosas como los jesuitas y a la relajación moral y ansias de lucro del clero. El texto no demuestra una irreligión militante, aunque si muestra una imagen desfavorable del grueso del clero, especialmente del regular, erigiendo la libertad de conciencia en valor supremo, incluso por sobre la homogeneidad religiosa 14.

El sentimiento regionalista crecía ante la actitud del Gobierno. Los silencios de éste ante el edicto fueron interpretados como una tácita tolerancia y se acusó al Ejecutivo de consentir "la posibilidad de un conflicto entre las autoridades civil y eclesiástica" con sus actitudes ${ }^{15}$. No era éste, aún, un anticlericalismo liberal, sino uno de raigambre regalista, partidario de una Iglesia sometida al poder civil. Esto nos muestra como el anticlericalismo podia ir de la mano con posturas regalistas, pese a que esta última doctrina incluia la noción de una religión oficial de Estado 16.

\section{PROTESTA ANTICLERICAL Y MOVILIZACIÓN SOCIAL}

Las protestas de El Copiapino contra el edieto continuaron. Al dia siguiente, el periódico publicó otro

\footnotetext{
if "Pastoraí del Arzobispo de Santiago", en Op. Cit.

is libid.

14 Sobre estas importantes distinciones dentro del campo anticlerical véase Remond, René 1983, "Anticlericalism: Some reflections by way of introductioni, en The Europein Studies Review Vol N"13, N², pp. 121-126.

12. "Vapor del Sud. Chile..t Opr Cir.

16. Sobre estas Posibles asociaciones en la América Latina del Siglo XIX, véase Cárdenas Ayala, Elisa 2005, La construcción de sen onden laico on América Hispana, Ensiayo de interpretacien sobre el siglo XIX, mimeo inédito, Guadalajara.
}

Revista de Mistoria, año 18, vols. 18-19, 2008-2009, pp. 197-211. 
artículo en primera plana, denunciando el Edicto en términos similares a los del día anterior, y haciendo un llamado al Ministro de Culto para que suprimiera o al menos lo modificara en las partes, que a juicio de los editorialistas, atacaba "la moralidad pública, la conciencia privada y viola las leyes nacionales poniendo en peligro una parte crecida de los habitantes de Chile"17.

¿A que peligro hacian referencia los redactores de El Copiapino? de los extranjeros:

Según ellos, el Edicto podria tener el efecto de movilizar a las masas populares católicas en contra

"El arzobispo sabe muy bien que el pueblo ignorante llama herejes y excomulgados a todos los que no haban el español y es a él a quien confian la calificación de la herejía y de los excomulgados; su edicto es un ataque directo e impío contra todos los extranjeros residentes en Chile, es una provocación que ojalá que no produzca las funestas consecuencias a que da lugar"18

¿Existía realmente este peligro?

Contamos con pocos testimonios sobre el tema. Según los recuerdos del viajero alemán Paul Treutler, quien entonces trabajaba como empresario minero y minerólogo en la ciudad, el Edicto habria sido traido a Copiapó por un grupo de sacerdotes jesuitas de Santiago. A la mañana siguiente de su llegada, ya se habria esparcido por la ciudad el rumor de que los jesuitas "habrian venido para excitar al pueblo contra los extranjeros, sobre todo contra los protestantes y los judios, para expulsarlos de la provincia y del pais". Treutler, junto a otros extranjeros residente en Copiapó, creian que "se habia procedido a formar una lista con los nombres de todos los extranjeros de Copiapó, la que se habria entregado a los jesuitas, a fin de que excitaran al populacho a expulsarnos o asesinarnos"19. Los rumores que circulaban por Copiapó tomaban la forma de una conspiración jesuítica seriamente planificada, destinada a eliminar los inmigrantes del pais excitando las turbas urbanas:

"El plan de los jesuitas era dar a conocer el edicto en el preciso momento en que los mineros, los bandidos y la chusma se habian reunido en gran número, era sin duda inteligente, pues podian usar como instrumentos a muchos de ellos, que se encontraban embriagados" 20 .

Treutler da por ciertos estos rumores. Sin embargo, al cotejar sus relatos sobre estos sucesos con los testimonios de los periódicos, hemos podido detectar varios errores. Además, los alegatos antijesuíticos de los diarios copiapinos apuntaban hacia la influencia de esta orden en círculo arzobispal y en la génesis del edicto, mas no hablan de su presencia en la ciudad nortina. No obstante, la publicación del edicto en la puerta de las iglesias, las esquinas y su repartición al público en el contexto de la llegada de grandes masas de peones mineros a festejar en la ciudad debe haber excitado el pánico entre los extranjeros residentes y, en general, entre gran parte de la alta sociedad Copiapina. Los rumores sólo deben haber acrecentado esta atmósfera. En todo caso, no debemos olvidar que la indignación moral y el apasionamiento que generó el edicto en Treutler pueden haber influido en la distorsionada visión que da de los acontecimientos, Quizás su propio testimonio al respecto puede ser considerado una fuente sobre las formas que adquiria $\mathrm{el}$ anticlericalismo, especialmente en su vertiente antijesuitica. En este sentido existia una mentalidad que tendía a asociarlos a la actuación conspirativa. A la vez, este texto refleja el resentimiento con que parte de la comunidad protestante residente en Copiapó puede haber recibido las endurecidas posturas de la Iglesia, las que en Chile se notaron desde la llegada del arzobispo Rafael Valentin Valdivieso.

Verdadera o no, la amenaza de una turba popular enardecida por la religión era percibida por los inmigrantes. Treutler recuerda que "como ya se habian reunido grandes masas humanas en la plaza principal, gritando y vociferando, uno de los más reputados dueños de minas envió por mi y otros compatriotas para que nos juntáramos en su casa, a fin de protegernos ${ }^{-21}$.

No es extraño que en este contexto los sectores reformistas copiapinos hubieran querido tomar la conducción de la movilización social. Asi, el dia 23 de diciembre vio la luz un nuevo número de El Copiapino.

17. "El Edicto Arzobrispal", en El Copiapino, Copiapd 21 de diciembre de 1853

is libid

14 Treutler, Paal 1958: Andanzas de un alemain en Chile. Santiago, Edtorial del Pacifico, pp. 166-167. (de ahora en adeiante Treutler).

so Ibidem.

$n$ Ibid. p. 166 
Ocupando toda la mitad izquierda de su primera plana, habia un manifiesto compuesto de dos párrafos, titulado Edicto Arzobispai:

"A TODOS LINIVERSALMENTE ORDENAMOS, BAJO PENA DE NUESTRO ARBITRIO, A MAS DE LAS QUE DISPONE EL DERECHO, QUE HAGAN ANTE NOS, O ANTE NUESTROS CONVISITADORES, LA DENUNCIA DE LOS QUE POR HECHO O PALABRA SEAN SOSPECHOSOS DE HEREJIA, EXCOMULGADOS, O QUE DE AI,GUNA MANERA PERVIERTAN LAS COSTUMBRES; EXHORIANDO Y ROGANDO EN EL SENOR A TODO AQUEL QUE TUVIERE QUE COMUNICARNOS CUALQUIER ASUNTO, SE DESNUDE DE TODA PASION Y MIRE EN LO QUE HACE UNICAMENTE A LA GLORIA DEL SENOR

HIRIENDO EL PRESENTE EDICTO EL. BUEN SENTIDO, LA CIVILIZACION Y LA GLORIA DEL. SENOR, CUYA MAJESTAD SE INWOCA HIPOCRITAMANTE, Y SIENDO POR OTRA PARTE, ANTISOCIAL, INHUMANO Y BÁRBARO, SE INVITA UNIVERSALMENTE A LAS PERSONAS DE SANO CORAZÓN CONCURRAN EL DOMINGO 25 DEL CORRIENTE A LAS SEIS DE LA TARDE A LA ESTACIÓN DEL FERRO-CARRIL DE ESTA CIUDAD, EN CUYO PUNTO SERA DICHO EDICTO QUEMADO PÜBLICAMENTE, COMO UN TESTIMONIO SOLEMNE DE REPROBACION Y DE QUE COPIAPÓ NO CONSIENTE NI CONSENTIRÁ IAMÁS, QUE EN SU SENO SE ABRAN LAS HOGUERAS DEL. SANTO OFICIO, - COPIAPÓ, DICIEMBRE DE $1853^{* 22}$.

Al parecer, la indignación contra el edicto habría prendido en diversos sectores. El Copiapino aludió a la "indignación general" que el Edicto "habria causado en este último ríncón de la república"23. Aunque con algunas imprecisiones cronológicas, Treutler avala estos dichos cuando sostiene que este habria sido arrancado de los lugares donde estaba pegado, para ser escupido y pisoteado 24 .

El Copiapino continuó la campaña contra el edicto el dia previo al programado para la quema, aunque ahora en un tono más ponderado, menos rico en denuestos. Acusaban al arzobispo de sabotear las providencias a favor de la inmigración extranjera tomadas por el Estado y de destruir la imagen de Chile en el exterior, contribuyendo a que en el extranjero se pensara que en Chile se conservaban "los mismos instintos y hábitos del tiempo del dominio de nuestra madre Patria" 25

"Parece que ciertos hombres quisieran alejarnos para siempre del contacto de las luces, inventando todos los modos de alejarlas de nuestro suelo. Quisieran hacer de Chile un nuevo Japón, un nuevo Paraguay, en una época en que todas las naciones tienden a estrechar lazos de mutua fraternidad. A este fin se dirigen nuestras leyes restrictivas, las ideas de intolerancia sostenidas de distintos modos por una parte de nuestro clero, y más que todo ese fatal edicto que ha excitado la animadversión de toda persona racional. En fin ya se arrojó la máscara, en adelante todos sabremos a que atenernos cuando cierta gente de corona llegue a balbucear palabras de tolerancia y libertad: Sabremos que es el abrazo de Judas ${ }^{126}$

Existen algunos antecedentes del ambiente de tensión vivido por la ciudad antes del acto de quema del Edicto. El Pueblo, periódico copiapino comprometido con una postura de oposición liberal, expresó sus dudas sobre la voluntad y capacidad de El Copiapino para congregar una manifestación antigobiernista y advirtió sobre la posibilidad de que el intendente disolviera la demostración "a culatazos", derivando los acontecimientos en hechos de sangre 27 .

Con algunas confusiones, los recuerdos de Treutler sosticnen que el edicto habria sido quemado el mismo dia 24 de diciembre, pues la indignación general no habría podido esperar un día más. Sin embargo, los testimonios de periódicos lo contradicen y dejan en claro que el acto se realizó el 25 de diciembre, dia en

22 "F.dicto Arzobispal", en EI Copiapino, Copiapá. 23 de diciembre de 1853. Las palabras destacadas, Hevaban en el texto original una letra hueca con reminiscencias guticas, quizás para mostrar una imagen medieval.

23 El Copiapino. Copiapo, 24 de diciembre de 1853.

14 Treutier, p. 167

Is El Copiapino, Copiapo, 24 de diciembre de 1853

In thid.

77. ES Puetio, Copiapo, 24 de diciembre de 1853, Si bien en las elecciones parlamentarias de 1855 el periodico Ei Puebio mostró una postura firmernente gobiernista, entre los ańos 1853 y 1854 demostró tendencias liberales y antigobiernistas. losé Antonio Iafuente, intendente de Atacama, denunció como en dicho diario "escribe un loven Zapata de Talea (revolucionario de Copiapó)" Vease la "Carta de José Antonio Lafuente a Manuel Montr", Copiapó, 9 de enero de 1854, en Archivo Nactonal. Fondo Fundación Manuel Mont1. Tomo IX, f. 196

Revista de Historia, año 18, vols. 18-19, 2008-2009, pp. 197-211. 
que estaba fijado 28 .

De lo que no quedó duda fue de la enorme magnitud alcanzada por el acto. Según El Copiapino, que como todo buen organizador de manifestaciones probablemente exagera las cantidades, se habrian llegado a congregar alrededor de 4.000 personas camino a la estación del ferrocarrii ${ }^{29}$. Una concentración de tal arrastre debe haber tenido un carácter interclasista, o por lo menos haber incluido también a sectores extraelitarios. El Pueblo ha dejado testimonio de cómo "toda la población de Copiapó" se dirigia hacia el sitio del acto ${ }^{30}$. El Copiapino sostuvo que "los artesanos, los comerciantes, los letrados, los mineros, las señoras a caballo y en carruaje, lo más escogido de nuestra población" se dieron cita en la reunión ${ }^{31}$. Con respecto a la filiación politica de los asistentes, El Copíapino sostuvo que al acto asistieron "los sujetos más influyentes de Copiapó, que han sostenido y sostienen al gobierno" ${ }^{32}$. Los oposicionistas liberales de El Pueblo también dieron su concurso.

Los extranjeros fueron parte central del acto. Según Treutler, "una delegación formada por los primeros ciudadanos de Copiapó", habria visitado a los extranjeros, para invitarlos a "dirigirse con toda confianza a la plaza principal", donde habrian sido recibidos con "grandes aclamaciones" 33 .

Los asistentes se habrian dirigido a la estación de tren. En el camino fueron interceptados por el Comandante de la Policía, quien tenía una orden del intendente para prohibir la reunión. El comandante comunicó las instrucciones de su superior, "suplicando urbanamente a las personas más visibles que se dispersasen". La marcha no se detuvo, aunque, según consta en El Copiapino, se habria desviado para quemar el edicto sobre los rieles del ferrocarril en una zona cercana a la indicada ${ }^{34}$. Los manifestantes no fueron reprimidos.

Tras la marcha, las copias del Edicto fueron quemadas en un acto solemne. Los presentes guardaron silencio, mientras veian cómo los documentos se reducian a cenizas. Desde afuera sólo llegaba un fuerte tan̂ido de campanas. Según los recuerdos de Treutler, "el pueblo" se "habia apoderado" de ellas durante el acto para hacerlas repicar ${ }^{35}$.

El periódico El Pueblo de Copiapó, sostuvo que al momento de incendiarse los edictos, el hombre que les prendió fuego habria pronunciado un discurso, diciendo que:

"Sobre los rieles que conducen la civilización las llamas que en otro tiempo quemaban a los que quisieron usar la libertad de pensar, reducirán a cenizas la orden inmoral del más honorable de los curiales chilenos" 36 .

Paul Treutler da una versión similar de los hechos, aunque con algunas diferencias. En sus memorias recordaba que tras apagarse la fogata, un hombre habria dicho que los copiapinos:

"quemaban libre y espontáneamente el salvaje edicto, en nombre de Copiapó, sobre los rieles que habian traído la ilustración la luz y el progreso de todo orden a la ciudad, y para exteriorizar al Arzobispo y a los jesuitas nuestro repudio y a los extranjeros nuestro respeto. ;Que se enteren los primeros del espiritu que reina en Copiapó en $1853 !^{\cdots 37}$.

Según el relato del alemán, a este discurso habrian seguido dos más. Uno, exactamente en las mísmas palabras que un artículo aparecido dos días después en el Copiapino, habria sostenido que:

\footnotetext{
If Confróntese los testimonios de El Pueblo, Copiapó, 26 de diciembre de 1853 y Ei Coplapino, Copiapo, 27 de diciembre de 1853 , con Treutler, p. 167.

27. "El 25 de diciembre", en El Copiapina, Copiapó 27 de diciembre de 1853.

90. El Pueblo, Copiapo, 26 de diciembre de 1853.

31 "El 25 de diciembre", en Op. Cit.

n2. "Cuatro palabras al colega", en Jbid.

3 Treutler, pp, 167-168. El viajero alemán muestra una visión de los hechos discordante con los testimonios de los dos periódicos. Segün 'Treutler, la quema del documento se habria verificado el dia 24, a instancias de la muchedumber indignada que no habria consentido un dia de espera para realizarla. La quema. que se eataba prodaciendo en un improvisado escenario frente a la lglesia. habria sido detenida por el intendente. Este ultima. pese a mostrarse contrario el edicto dijo que no podia permitir tal alteración del orden puiblico. Razón por la que los concurrentes marcharon pacificamente a la linea del ferrocarril para realizar su cometido.

34 "El 25 de diciembre", en Op. Ort.

15 Treutler, p. 168,

4. El Pueblo, Copiapó, 26 de diciembre de 1853.

3) Treatler, p. 168.
} 
"Dos épocas gloriosas ha tenido Chile; la de nuestra emancipación politica verificada el año diez, en que por la razón o la fuerza se elevó al rango de nación libre e independiente y el 25 de diciembre de 1853 en que el pueblo en masa protestó contra los principios del espionaje elevados a máximas religiosas. En este dia ha proclamado realmente su emancipación de toda influencia jesuítica, de todo principio retrógrado, y ha presentado al Gobierno su apoyo moral y físico para marchar resueltamente por el camino de la reforma y del progreso" 38

$\mathrm{Y}$ otro, en que el autor:

"después de pedir a la asistencia que practicara la amistad y el amor en el trato con sus congéneres y de expresar su deseo de que cada extranjero encontrara en Chile una segunda patria, vivó a los extranjeros, lo que el gentío acogió con grandes aclamaciones" 39

Tras este acto, los presentes se retiraron pacificamente a celebrar las festividades navideñas. Los extranjeros se integraron sin ningún problema a ellas: habían pasado a ser los festejados, el centro de atención. Así, "bailaban con las hijas y bebian con los hijos de la ciudad". Las celebraciones continuaron en la tarde con el lanzamiento de fucgos artificiales, dándoles tintes de festividad y satisfacción por el acto realizado 40 .

Llama la atención el cariz festivo que tomó la ocasión, a la vez que la solemnidad del propio acto de quema. ¿Puede ser considerado un acto de sacrofobia? Los propios actores no lo pensaron de esta manera ${ }^{41}$. Es más, como hemos visto, lo interpretaron como una muestra de respeto a una religión más auténtica y de rechazo a su instrumentalización por parte de la autoridad eclesiástica. Sin embargo, es una clara muestra de desacralización de la autoridad arzobispal. A la vez, puede ser expresión del desarrollo de un tipo de religiosidad más intimista e individual, que eleva la conciencia individual por sobre las autoridades religiosas externas. Quizás le daban a estas ideas un carácter sagrado, que tendria expresión en la virulencia de su defensa y en la solemnidad adquirida por el acto ${ }^{42}$.

Los testimonios sobre el carácter interclasista que alcanzó la manifestación llaman la atención. Sabemos que tuvieron participación artesanos y sospechamos, por la gran cantidad de asistentes, que también se hicieron parte otros sectores del mundo popular. Nos encontramos, posiblemente, ante un caso de anticlericalismo popular, en que masas del bajo pueblo estarian dispuestas a movilizarse en contra de autoridades eclesiásticas. En general, diversos estudios han tendido a resaltar el carácter "tradicionalista" de las turbas urbanas, visión, que como vemos en los testimonios de la prensa y de Treutler, habria sido sostenida por las propias élites copiapinas a mediados del siglo $\mathrm{XIX}^{43}$. No es extraño que sectores como los artesanos, altamente politizables, fueran proclives a absorber estas ideas. Sin embargo, la existencia de masas más grandes del mundo popular adhiriendo a estas causas abre un interesante campo de estudio. Quizás la desarraigada vida itinerante del peonaje minero en el desierto, caracterizada por su falta de respeto a toda autoridad existente, influyó en la ausencia de concepciones religiosas más sólidas ${ }^{44}$. Tampoco es extraño que el rechazo violento a los "conspiradores" que suplantarian a la "verdadera iglesia", categoria que podria ser atribuida a los jesuitas o a ciertas autoridades eclesiásticas, estuviera acompañada de una profunda religiosidad, como ya lo ha analizado Hobsbawm para el caso europeo ${ }^{45}$. De hecho la prensa liberal copiapina apuntó su discurso en este último sentido 46 .

98 thid. p. 169 y Fl Copiapine, Copiapo, 27 de diciembere de 1853. Fs probable que Treutler haya guardado un ejemplar del Periódico y que to haya ocupado como referencia al momento de escribir sus recuerdos.

34 Treutlet, p. 169

4. Ithid, p. 169

"Sobre la Sacrofobin vease el interesante analisis realizado por Delgado Luis, Manuel 1989, "La antirreligiosidad popular en Espana", en Santalo, Alvaro, et al : La neigigosidad popular, Barcelona, Fundación Machado/Ed. Anthropos, Vol 1. p. $499-502$.

12. En este sentido es interesante tomar la noción de "transferencia sacra (...) de las cargas afectivas y emocionales antes ligadas a las representaciones cristianas" a "valores nuewos, familiares, civicos y patrioticos". Véase Chartier, Roger 1995, Espacio puiblica. coitica y desacralización en ef siglo XVIII: las arigenes culturales de la Revoluesón Fnencesa, Barcelona, Gedisa, p. 125, Consideramos apropiado tratar bajo este prisma la desacralizachón de la autoridad eclestastica y la sacralizacón del pluralismo religioso.

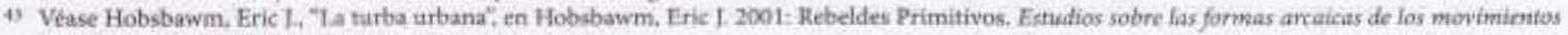
sociales en los siglos XIX Y XX., Barcelona, Critica, p.161.

4 Sobre el tema, vẻase lllanes, Maria Angelica 2003, "Azote, Salario y Ley Disciplinamiento y rebeldia de la mano de obra en la mineria de Atacama":

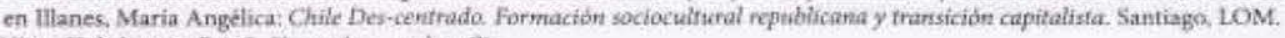

45 Vease Hobsbawm, Eric T., 'La turba.... . , loc. Cit.

4h Es intersante observat como el anticlericalismo popular se ha fundido con los provectos laicizantes del republicanismo y el liberalismo, en una suerte de movilización "populista". Para el caso espahol, véase De la Cueva, Julio, "La democracia frailofoba". Democracia liberal y anticlericalismo duramte la restauracióni, en Suarer Cortina, Mantiel (Ed,) 1992, La restauración entre el libenaítsmo y la demacradia, Madrid, Alianza, p. 236 y 254 a 263.

Revista de Historia, año 18, vols. 18-19, 2008-2009, pp, 197-211. 


\section{LAS FORMAS DEL ANTICLERICALISMO COPIAPINO}

Las reacciones posteriores confirman esta apreciación. Al día siguiente, tanto los sectores mâs liberales como los gobiernistas se congratulaban por el acto realizado. Los liberales, a través de El Pueblo, sostuvieron que la quema habia sido un acto de desagravio para Chile, que reivindicaba la diginidad del pais. Para ellos se trataria de un acto necesario para seguir atrayendo la inmigración extranjera y un rescate de los principios primigenios del cristianismo: una iglesia ajena al poder y a las persecuciones, centrada en los valores de la caridad y resignación. Principios que habrian sido desnaturalizados por la clerecia chilena ${ }^{47}$. Los sectores gobiernistas, aún, representados a través de la redacción de El Copiapino, también se felicitaban por lo acaecido, sin embargo esta vez moderaron su lenguaje, evitaron ataques al clero en general, $y$ en forma mucho más mesurada que antes, criticaron "al pequeño círculo jesuitico que rodea a la curia eclesiástica, y que extiende su triste influjo a las personas más elevadas de Chile". A esto añadieron declaraciones de apoyo al Gobierno, y anhelos de que este "marchara resueltamente por el camino de la reforma y el progreso" 48 . Quizás, como en otras regiones de América Latina, el apoyo a los protestantes se transformó en un modo de critica de los sectores regionales modernizantes, descontentos con administraciones centrales de corte más tradicional ${ }^{49}$. Las elites copiapinas veian en la inmigración extranjera, en especial la europea, una de las claves del progreso económico y se oponían a las reticencias de los sectores conservadores del país.

Llama la atención, durante el acto y las polémicas posteriores, la ausencia de ataques al clero local. Al parecer, parte de éste habria compartido el rechazo al Edicto. Testimonio de ello son los recuerdos de Treutler, que mencionan que el mismo día del acto, el cura párroco de Copiapó visitó en forma privada a varios extranjeros residentes en la ciudad. Junto con demostrarles abiertamente su indignación con el edicto, los invitó a su hogar, convite que los extranjeros habrian aceptado gustosos ${ }^{50}$. Claramente se trataba de una forma de desagravio de parte de la autoridad del clero local. El propio clero secular podia hacer suyos algunos elementos tomados del anticlericalismo, como el rechazo a ciertas órdenes religiosas, y podia aprovechar de utilizarlo para repudiar ciertas órdenes superiores indeseables, sobre todo cuando se encontraba comprometido con el espíritu regionalista. Bruno Zavala, cura párroco de Copiapó, demostró sus simpatias regionalistas seis años más tarde, bendiciendo a las tropas del "ejercito constituyente", cuando partian rumbo al sur a enfrentar al Gobierno central 51 .

Según todas las fuentes disponibles, la propia actuación de las autoridades gubernamentales presentes, intendentes y jefes de policía, oscilaba entre la permisividad y el apoyo silencioso. Estas mismas fuentes no nos muestran manifestaciones de rechazo al acto en Copiapó.

El ambiente de apoyo festivo a la quema se extendió churante más dias, y tuvo expresión en el teatro, donde fue presentado el drama Carlos $/ /$ el hechizado. Esta obra extremadamente anticlerical del liberal español José Antonio Gil de Zárate, causó gran escándalo cuando se estrenó en España. En este drama, uno de los personajes, fray Froilán Diaz -o el Fraile Diaz como despectivamente lo llamaba El Pueblo de Copiapó en su sección sobre teatro-, se siente enormemente atraído por Inés, hija secreta de Carlos II. A sus no correspondidos lances amorosos, fray Diaz contestaba denunciando a Inés ante la inquisición por brujeria, acusándola de ser la causante de los terribles males que aquejaban al Rey ${ }^{52}$. La obra tuvo una gran audiencia en Copiapó, y las fuentes coinciden en mostrar como sus pasajes desataron grandes ovaciones y manifestaciones de entusiasmo de parte del público, el que asimilaba las demasias del clero mostradas en la obra con las intenciones atribuidas al Arzobispo de Santiago en su edicto ${ }^{53}$

El uso de estas analogias debe haber tenido un carácter jocoso: la asimilación del arzobispo a un fraile libidinoso puede haber contribuido a demoler el aura sacra de de su autoridad, consiguiendo una apelación emocional, quizás de mayores efectos que las protestas publicadas en los periódicos. Al respecto, hay que tener en cuenta el fuerte potencial pedagógico que se le atribuia al teatro ${ }^{54}$.

47. El Puebla Coplapó, 26 de diciembre de 1853.

* El Coplapina Copiapó, 27 de diciembre de 1853.

6s Sobre este tema, véase Bastian, Jean Pierre 1994, Protestantismos y modernidad latinoamericana. Historia de anas minorias religiosas en America Latina, Mexico, Fondo de Cultura Económica. p. 122

\$0 Treutler-pp. 169-170.

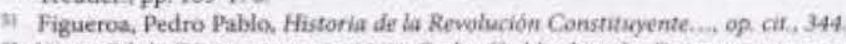

52 Véase Gil de Zarate, Antonio 1860. Carlos II d hechitada Drama en cinco actos y en verso, Valparaiso, Imprenta del Mercurio de Santos Tornero, Para los comentarios, véase "Teatro", en El Pueblo, 28 de diciembre de 1853.

32 "Colaboradores. Beneficio de la senorita Vera Rendón", en El Pueblo, Copiapó, 27 de diéembre de 1853.

4 Rodriguez Silva. Andrea 2003: Los origrnes del teatro en Copiapol Consume. Placer e Irstracción. 1847-1867. Tesis para optar al grado de Magister en Historia Mención en Historia de Amética, Santiago, Universidad de Chile y Molina, Eugenia: 2004 "Pedagogia civica y disciplinamiento social: 
El Copiapino mostraba estas exhibiciones de teatro como una manifestación del progreso alcanzado por Copiapó, contraponiéndolo a un espiritu retrógrado atribuido a Santiago:

"Anoche más de un novel santiaguino ha dejado en el teatro el Cascarỏn. Testigos de las ideas de civilización que dominan en nuestra sociedad, tendrán aunque les cueste trabajo, que abandonar los hábitos de hipocresia, $y$ amoldarse a las ideas verdaderamente humanitarias" 55 .

Como podemos ver, El Copiapino se congratulaba de sus actos. Sus páginas exhibian correspondencia supuestamente venida de Santiago. Ésta habria felicitado al pueblo de Copiapó por haber liderado la protesta y resaltaba el rol de vanguardia adquirido por la capital de Atacama en la lucha por las libertades ${ }^{56}$. Esta sensación de liderazgo se vio acrecentada cuando el diario de Avisos de Valparaíso, llamó a realizar un acto similar para el $1^{\circ}$ de enero de 1854 . Dicha manifestación fue abortada por el intendente, quien la prohibió y envió tropas al lugar donde se había programado su realización. Los redactores de El Copiapino criticaron la medida de la intendencia porteña y defendieron el derecho a realizar manifestaciones, siempre que no alteraran el orden público. Asi sostuvieron que "cuando en Chile tengamos si es posible un meeting cada semana, para tratar la cosa pública, entonces será lo que hoy falsamente se apellida, república" 57 .

Las criticas de los sectores cercanos al Arzobispado no tardaron en llegar. El Copiapino se vio envuelto en una polémica de prensa con la Revista Católica, órgano de prensa del Arzobispado. La Revista publicó supuestas cartas de protesta de católicos santiaguinos, que consideraban la quema como una "inconcebible osadia", al mismo tiempo que criticaban el violento lenguaje con que el diario atacameño se dirigia a los sectores más conservadores de Santiago ${ }^{58}$. La redacción de la Revista Católica califícó la quema del edicto como un "atentado inaudito". En sus ataques definieron el acto como una agresión directa al catolicismo, realzando el carácter de éste como la religión de "inmensa mayoria de los chilenos" y como "religión del estado".

"¿Es acaso únicamente la persona de nuestro metropolitano la que se insulta de esta manera soez e infame? No; es la autoridad eclesiástica que acata y venera la mayoria del pueblo chileno, es nuestra santa religión, que recibe el vejamen en nombre de su sagrado representante, son nuestras leyes, nuestras tradiciones, nuestras costumbres, es en una palabra, la fe de nuestros padres que se vilipendia por unos cuantos hombres sin pudor que se burlan y maldicen todo lo que huele a piedad y religión, de todo lo que se eleva sobre la religión animal en que ellos viven" 59 .

Los argumentos de la prensa católica realzaban de este modo la unión de patria y religión, y calificaban los ataques a la autoridad eclesiásticas como atentados a la nación.

Con respecto a las denuncias del El Copiapino, que achacaban al Edicto querer "perturbar el reposo de los extranjeros disidentes avecindados en Chile", La Revista Católica acusaba al diario nortino de esgrimir argumentos cargados de "mala fe". La Revista sostenía que los protestantes no estaban sujetos a las autoridades eclesiásticas católicas, por lo que el edicto no tendria ningún valor sobre ellos:

"No se manda pues, ni puede mandarse la denuncia de los protestantes ni de ningún otro que haga pública profesión de una religión distinta de la nuestra, sino la de los que se titulan católicos y conservan este velo hipócrita para hacer más segura su traición a su antigua creencia, para herir sin ser conocidos la fe de los sencillos creyentes. Estos lobos rapaces cubiertos con piel de oveja"60.

\footnotetext{
representaciones sobre el teatro entre 1810 y 1825", En Prismas, Revista de historia intelectual, N" 8, pp. 35-58.

35 "Teatro", en El Copiapino, Copiapó. 28 de diciembre de 1853.

56 "Santiaga Correspondencia del Copiapino", en El Copiapino, Copiapo, 5 de enero de 1854.

57 Véase "COMO SE QUEMÓ EN VALPARAISO EL. EDICTO ARZOBISPAL" en El Copiapino, Copiapo, 7 de enero de 1854 . En Valparaiso se habia producido una polémica entre el diario El Mercario y las autoridades eclesíásticas. El diario porteno habia rechazado el edicto, sosteniendo que afectaba los intereses de los inmigrantes protestantes. Véase El Menurio, Valparaiso y La Revista Catolica, Santiago, a lo largo de diciembre de 1853 y enero de 1854. Lamentablemente, no hemos podido encontrar nùmeros del diario Avisos para estos años.

s9 "CORRESPONDENCIA DE L,A REVISTA CATCLICA. Voto de reprobació"i en La Revista Católica, Santiago, 2 de enero de 1854

\% "Atentado Inaudito" en lbid.

6e. Ibid.
}

Revista de Historia, año 18, vols. 18-19, 2008-2009, pp, 197-211. 
De este modo, la postura del arzobispado reducia el àmbito de la libertad de conciencia al propio individuo aislado. Dentro del Estado Católico, la jerarquia eclesiástica no reconocia fronteras sociales de "lo privado" -como lo fue el ambito intimo de la familia en las discusiones parlamentarias estudiadas por Sol Serrano para fines de la década de 1850 y la de 1860-, por lo que cualquier manifestación externa contraria a la Iglesia institucionalizada era reconocida como un atentado contra la nación ${ }^{61}$. La jerarquia eclesiástica se atribuia el deber de aplicar sanciones espirituales y movilizar presiones sociales en contra de quienes se dijeran católicos, pero sustentaran doctrinas consideradas erróneas. Se creía que las autoridades politicas y administrativas tenian el deber de apoyar este cometido.

Por lo mismo, las críticas de la prensa católica no sólo apuntaban hacia los organizadores y participantes del acto, también cuestionaban la actuación de las autoridades civiles, especialmente la del Intendente. Los redactores de La Revista Católica repudiaron el silencio de las autoridades civiles de Copiapó ante la quema, y vaticinaron que dicho tipo de actitudes abririan la puerta al desorden, el que finalmente terminaria arrastrando a la propia autoridad civil.

"(...) los cimientos del orden están hondamente conmovidos; la libertad del magistrado es una palabra sin sentido, el respeto a la autoridad una quimera, y la religión, que acatan millón y medio de habitantes; que es la única del pais; la esperanza y la salvaguardia de nuestra patria, es insultada públicamente en presencia del magistrado encargado de hacerla respetar. No se engañe nadie, creyendo que es posible perder el respeto a la religión y sus ministros, sin perderlo también la autoridad civil. Hoy se burla a un arzobispo; mañana se burlará a un intendente, a un Congreso, a una Corte de Justicia, al mismo Presidente de la República: el ejemplo está dado, y la fuerza del ejemplo es poderosa. La guerra que se hace al altar no termina en éste, cuando los altares se vilipendian, bambolean los gobiernos" 62 .

Haciendo probablemente alusión a la Revolución de 1848, las advertencias de La Revista Católica recordaban a los lectores sobre la agitación socialista que había vivido Francia, para sostener que sólo "los poderes enérgicos salvan sociedades" 63 . La asociación entre religión institucional y orden, tanto político, como social quedaba patente en las líneas de la prensa católica capitalina.

Las réplicas de los involucrados no se hicieron esperar. Los sectores liberales, representados en la redacción de El Pueblo, sostuvieron que la ejecución del Edicto Arzobispal hubiera debido "imitarse en los demás pueblos de la república". Criticaron que se les tildara de herejes, e hicieron manifestaciones de una profunda religiosidad. Sin embargo, su religiosidad era critica de las autoridades eclesiásticas en general. Intentando rescatar el espiritu primitivo del cristianismo, al que atribuian un profundo "espiritu de caridad" y de "amor por el linaje humano", criticaban a la jerarquia eclesiástica, la que habria:

"conseguido destruir el régimen orgánico y primitivo de la antigua disciplina de la Iglesia fundada por Jesucristo, los apóstoles y sus inmediatos sucesores, y sustituir otro puramente humano y en gran manera pernicioso, introducido con falsas decretales, y defendido después con sofisterias y maniobras sugeridas por la ambición y la codicia (...) la doctrina de Jesucristo es tan perfecta en su esencia, que descubrir errores, reformar las preocupaciones y acabar con las supersticiones de que nuestra ceguera la ha revestido, es volverla a su pureza primitiva, es quitarles sus vestidos terrestres, es generalizar la vida y la libertad de todos los pueblos, según las palabras divinas de Jesucristo ' $L a$ verdad os hará libres. ¡ CCuadro sublime de caridad y de grandeza! „Primera página de la historia de nuestra religión, que probablemente será también la última; porque hemos de volver a lo pasado, toda vez que lo pasado se presenta más adelantado para nosotros!. El punto de partida y el punto de llegada se tocan por el doble atractivo de la sencillez y la verdad" 64 .

La vuelta a esta comunidad primitiva de creyentes implicaba una fuerte critica al clero de su tiempo y a sus jerarquías. Al mismo tiempo tenia un impresionante carácter utópico. Podemos observar que se trata

61 Serrano, Sol 1999, 'La definición de lo público en un Estado catolico", en Esnudiar Públices, N 76, Primaxera, p. 217.

62 "La tumba de la libertad del magistrado y del orden, abierta en Copiapó el 25 de diciernbre de 1853 ", en La Kevista Catótica, Santiago, 21 de enero de 1854 .

63 loial.

64 "Fiecución del Fdicto Arzobispart, en Fi Pueblo, Copiapb, 3 de febreto de 1854 
de una desinstitucionalización de la creencia más que una pérdida de la fe. Así, estos sentimientos religiosos podian estar acompañados de fuertes ataques a la iglesia institucional, especialmente cuando se la atacaba por intolerante:

"Por fortuna los autores de la ejecución del Edicro Arzobispal han nacido en el siglo XIX: pues si les hubiera tocado nacer en el siglo XVT les habria cabido la suerte de ser amarrados a un poste y quemados vivos" 65 .

Algo parecido sucedia en el caso de los sectores politicos copiapinos más proclives al regalismo. Aunque criticaban a las jerarquias santiaguinas, al jesuitismo y a las actitudes intolerantes, no hicieron una crítica tan radical a la institucionalización de la Iglesia. El Copiapino se manifestó a favor de la "sana moral y la verdadera religión". Calificó a la Revista Católica como el "órgano fiel del jesuitismo de Santiago y defensor de las ideas retrógradas y antisociales que vomita cierta pandilla de corona" 66 . Después de descalificar a la prensa católica, pasaba a publicar, en "beneficio de la masa bruta de Santiago", la "Idea del derecho canónico por Mr. Bertrand. Primer pastor de la Iglesia de Berna".

La publicación de esta obra no puede pasar inadvertida al análisis. Jean Elie Bertrand, descendiente de hugonotes franceses, pastor protestante y figura epónima de la Iglesia Reformada de Berna, fue enciclopedista, amigo de Voltaire, además de uno de los más importantes precursores de la sismologia 67 . El hecho de que la prensa regalista de Copiapó hiciera un aporte al debate sobre las relaciones iglesia-estado con los tratados de un protestante, enciclopedista y cuasi-volteriano refleja su desapego a las doctrinas oficiales imperantes en el catolicismo.

En todo caso, la obra del pensador suizo se adaptaba perfectamente al pensamiento de esta élite que pretendia sujetar la iglesia al poder estatal. En la obra de Bertrand, la "jurisprudencia eclesiástica" se reduciria a ser la "exposición de los privilegios concedidos a los eclesiásticos por los soberanos que representan la Nación”. A su juicio, esta sujeción del poder eclesiástico al civil se haría necesaria debido a que la separación de poderes derivaria en conflictos interminables que destruirian a las naciones a través de guerras civiles, anarquia y tiranias. La sujeciōn de los eclesiásticos al orden civil debería ser total:

${ }^{4}$ (...) en una religión en la que Dios es representado como autor de ella, las personas, sus bienes, sus pretensiones, la manera de ensenar la moral, de predicar el dogma, de celebrar las ceremonias, las penas espirituales, todo en una palabra lo que interesa al orden civil, debe estar sometido a la autoridad soberana del príncipe y a la inspección de los magistrados ${ }^{n} 68$.

En el pensamiento de Bertrand se reconocian bienes sociales en la religión, cuales serian "mantener a los hombres en el orden, y hacerles merecer las bondades de Dios por la Virtud". Sin embargo, se reducia el poder coercitivo de los eclesiásticos al minimo posible: deberian enseñar con su ejemplo, con conscjos, amenazas de penas venideras o de bienaventuranza en el más allá. No podrian ejercer coerción en las conciencias de los hombres mediante otro tipo de penas, estipulando la libertad de conciencia como un bien fundamental. Incluso la expulsión de alguien de la Iglesia, por medio de la excomunión, deberia ser hecha con la anuencia del gobernante. Esta se reduciria a un simple problema de conciencia individual, que no tendria implicancias en ninguno de los derechos del afectado en el orden civil. En este sentido, el pensador rebajaba el rol mediador de los sacerdotes, diciendo que estos podrian actuar movidos por impulsos erróneos, por lo que la excomunión no generaria por si misma ningún castigo para la vida eterna 69

La argumentación de El Copiapino no se quedó sólo en estos principios. En un lenguaje virulento, calificó la intevención de la revista católica como un "miserable artículo". Al mismo tiempo, y en una retórica mareadamente regionalista, se preguntaba si sus redactores pensarian que:

"Copiapó es un pueblo de estúpidos, de rotos santiaguinos que no saben distinguir lo que es de Dios y lo que es del César, y que se puede conmover con vanas declaraciones de impiedad,

\footnotetext{
65. Ibid.

at "La Revista Católica", en El Copiapina Copiapó, 3 de febero de 1854

67. Crowley, Francis 1., 1959 "Pastor Bertrand and Voltaire's Lisbonc", es Modern Language Notes, Vol, 74. No. 5, pp: 430-433.

68 "Idea del derecho canónico por Mr. Bertrand. Primer pastor de la Iglesia de Berne". en Ibid.

69 Vease la continuación de la "Idea del derecho canónico por Mr. Berirand. Primer pastor de la tglesia de Berna", en El Copiapena Copiapó, 6 de febrero de 1854 .
}

Revista de Historia, año 18, vols. 18-19, 2008-2009, pp. 197-211. 
herejia, excomuniỏn y otras tretas semejantes, propias de la sagrada milicia jesuitica" 70 .

El rol mediador del sacerdote católico y la sacralidad de sus acciones se veian cuestionadas mediante estas palabras. La critica apuntaba a los jesuitas, sin embargo, en el camino llegaba a devaluar el rol del sacerdote y la autoridad del clero en materia de doctrina. La redacción calificaba a lo jesuitas de "murcićlagos político-religiosos, dotados de una "hidrópica sed de dignidades" y contraponian su acción a lo que denominaba el "mérito del verdadero sacerdote":

"que enjuga las lágrimas en el lecho del dolor, que reparte la palabra divina a los pueblos del campo, que asiste a los enfermos en los hospitales, que instruye a los jóvenes en las escuelas, que evangeliza al infiel en los campos de Arauco" 71 .

La crítica al clero ansioso de poder y conspirador se contraponia a la de los sacerdotes "útiles", funcionales a las necesidades sociales y a la acción del estado.

Exaltación de la libertad de conciencia, reducción del poder del clero y sujeción de este al estado. Los ideales de los sectores representados por El Copiapino coincidian con los de este teórico protestante. Regalistas, anticlericales y partidarios de la tolerancia, mas no antirreligiosos.

\section{CONCLUSIONES}

El "motin" antiarzobispal de 1853 deja a la vista como regionalismo y anticlericalismo iban de la mano en Copiapó, unidos por un discurso modernizador que menospreciaba el tradicionalismo del Chile central y resentia el peso excesivo de la capital. En este contexto, la tolerancia a los protestantes, y a los extranjeros en general, fue asumida como una cuestión de principios por las élites politicas reformistas, tanto las liberales como las gobiernistas. El motín fue vivido por sus protagonistas como la defensa de una comunidad que podia verse desgarrada por la intrusión de la vigilancia eclesiástica, pero también fue el catalizador de conflictos politico-religiosos que veian incubándose desde antes.

Liberales y gobiernistas copiapinos demostraron un fuerte anticlericalismo. Los motivos del antijesuitismo y el anqtiinquisitorialismo estuvieron siempre presentes en su discurso, al igual que las criticas a las ansias de poder, la vida disipada y la inutilidad de gran parte del clero. La libertad de conciencia fue ensalzada como un valor supremo y las autoridades religiosas llegaron a verse despojadas de respeto a su investidura y de su sacralidad. Las posturas de ambos grupos no eran antirreligiosas, pero si demostraban distintos grados de anticlericalismo. Los liberales llegaban a cuestionar la idea de religión institucionalizada, y la sustituian por una esperanza utópica de retorno al cristianismo primitivo, una iglesia ajena al poder y unida por las ideas de caridad y fraternidad universal. Los sectores gobiernistas, aunque ya descontentos, apuntaron sus reclamos a someter al clero al poder civil, en posturas de un talante más bien regalista.

Los altos grados de movilización social alcanzados reflejan la difusión de esta cultura anticlerical en diversos sectores de la población, mostrando importantes niveles de secularización. Pero, teniendo en cuenta que las posturas alternativas no eran de rechazo a la religión ¿de qué tipo de secularización hablamos?

Quizás el proceso de secularización de las sociedades occidentales no apunta necesariamente hacia un debilitamiento de la religiosidad, sino al desarrollo de nuevas formas más individualistas de vivirla. Este fenómeno ha sido analizado para nuestros tiempos desde el punto de vista del consumo de religión, el que para algunos autores remplazaria a la obligatoriedad coercitiva por la elección por parte de los individuos 72 . Uno de los aspectos más importantes de esta secularización puede ser la sacralización de este principio de pluralismo religioso. El anticlericalismo, en este caso, se desataria al verse violentado este principio.

En todo caso, es necesario tener en cuenta que para analizar las formas adquiridas por el anticlericalismo no se deben mirar en forma exclusiva a las ideas de mayor vuelo intelectual. Las odiosidades desatadas en las virulentas controversias politicas cumplian un rol importantisimo en la propia radicalización de las posturas. Es imprescindible observar los lenguajes de los actores y las dinámicas que éstos generaban. Esto sobre todo en contextos de amplias movilizaciones sociales como el que acabamos de estudiar.

\footnotetext{
즈 "Revista Católica", en El Copiapina, Copiapo, 7 de febrero de 1854.

7 Ibid.

22 Davie, Grace, 2004 "New approaches in the sociology of religiont ar westerm perspective", en Social Compass, Vol. 51, N\%1
} 


\section{BIBLIOGRAFIA Y FUENTES}

\section{FUENTES PRIMARIAS}

Archivo Nacional. Fondo Fundación Manuel Montt. Tomo IX El Copiapino, Copiapó, noviembre de 1853 - marzo de 1854 El Mercario, Valparaiso, noviembre de 1853 - marzo de 1854 El Norte, Copiapo, 1858

El Pueblo, Copiapó, noviembre de 1853 - marzo de 1854

La Revista Católica, Santiago, noviembre de 1853 - marzo de 1854

Arzobispado de Santiago, Boletín Eclesiástico o sea colección de edictos, estatutos y decretos de los prelados del Arzobispado de Santiago de Chile. Formada por el presbitero José Ramón Astorga. Secretario del mismo arzobispado, Santiago, Imprenta de la Opinión, 1861.

Censo Jeneral de la Republica de Chile. Levantado en abril de 1854, Santiago, Imprenta del Ferrocarril, 1854 Gil de Zárate, Antonio: Carlos II el hechizado. Drama en cinco actos y en verso, Valparaiso. Imprenta del Mercurio de Santos Tornero, 1860

Treutler, Paul: Andanzas de um alemán en Chile, Santiago, Editorial del Pacifico, 1958

\section{BIBLIOGRAFIA SECUNDARIA}

Bastian, Jean Pierre. 1994. Protestantismos y modernidad latinoamericana. Historia de thas minorias religiosas en América Latina, México, Fondo de Cultura Económica.

Cárdenas Ayala, Elisa. 2005. La construcción de un orden laico en América Hispana. Ensayo de interpretación sobre el siglo XIX, mimeo inédito, Guadalajara.

Chartier, Roger. 1995, Espacio público, critica y desacralización en el siglo XVIII: Los origenes culturales de la Revolución Francesa., Bancelona, Gedisa.

Collier, Simon 2005. Chile. La construcción de una república. 1830-1865. Politica e ideas, Santiago. Ediciones Universidad Católica de Chile.

Crowley, Francis J. 1959, "Pastor Bertrand and Voltaire's Lisbone", en Modern Language Notes, Vol. 74, N. 5, May, .

Davie, Grace. 2004. "New approaches in the sociology of religion: a western perspective", en Social Compass, Vol. $51, \mathrm{~N}^{\circ} 1$.

De la Cueva, Julio. 1997. "La democracia frailófoba". Democracia liberal y anticlericalismo durante la restauración", en Suárez Cortina, Manuel (Ed.), La restauración entre el liberalismo y la democracia, Madrid. Alianza, .

Delgado Luis, Manuel. 1989. "La antirreligiosidad popular en España", en Santaló, Ảlvaro, et al.: La religiosidad popular, Barcelona, Fundación Machado/Ed. Anthropos. Vol I.

Donoso, Ricardo 1946. Las ideas politicas en Chile, México D.F., Fondo de Cultura Económica.

Figueroa, Pedro Pablo.1889, Historia de la Revolución Constituyente (1858-1859), Escrita sobre documentos completamente inéditos, Santiago, Imprenta Victoria, de H. Izquierdo y Cía.

Gazmuri, Cristián 1998, El " 48" Chileno. Igualitarias, reformistas, nadicales, masones y bomberos, Santiago, Editorial Universitaria.

Hobsbawm, Eric J. "La turba urbana", en Hobsbawm, Eric J. 2001:Rebeldes Primitivos, Estudios sobre las formas arcaicas de los movimientos sociales en los siglos XIX y XX, Barcelona, Critica.

Illanes, María Angélica, "Azote, Salario y Ley. Disciplinamiento y rebeldia de la mano de obra en la mineria de Atacama", en Illanes, Maria Angélica 2003; Chile Des-centrado. Formación sociocultural republicana y transición capitalista. Santiago, LOM.

Illanes, Maria Angélica, "Proyecto comunal y guerra civil. 1810-1891", en Illanes, Maria Angélica 2003. Chile Des-centrado. Formación sociocultural republicana y transición capitalista, Santiago, LOM.

Molina, Eugenia. 2004: "Pedagogia civica y disciplinamiento social: representaciones sobre el teatro entre 1810 y $1825 "$, En Prismas, Revista de historia intelectual, No 8 , .

Remond, René, 1983, "Anticlericalism: Some reflections by way of introduction", en The European Studies Review, Vol. $\mathrm{N}^{\circ} 13, \mathrm{~N}^{\circ} 2$,. 
Rodriguez Silva. Andrea, 2003. Los origenes del teamo en Copiapó. Consumo, Placer e Instrucciòn. 1847 . 1867, Tesis para optar al grado de Magister en Historia Mención en Historia de América, Santiago, Universidad de Chile.

Scully, Timothy R. 1992. Los partidos de centro y la evolución politica chilena, Santiago, CIEPL AN-Notre Dame.

Serrano, Sol, 1999 "La definición de to público en un Estado católico", en Estudios Püblices, No 76 , Primavera.

Zeitlin, Maurice. 1984 . The civil wars in Chile (Or the burgeois revolutions that never were), Princeton, Princeton University Press, .

\section{ANEXO: EDICTO PARA LA VISTTA ARZOBISPAL}

Arzobispado de Santiago, Boletin Eclesiástico o sea colección de edictos, estatutos y decretos de los prelados del arzobispado de Santiago de Chile. Formada por el presbitero José Ramón Astorga. Secretario del mismo arzobispado, Santiago, Imprenta de la Opinión, 1861, Libro Sétimo, p. 54

Nos el Dr. D. Rafael Valentin Valdivieso, por la gracia de Dios y de la Santa Sede Apostólica, Arzobispo de Santiago de Chile, etc., etc., A todos los que las presentes tocaren, salud en el señor.

Creyendo que con el auxilio de la Divina Providencia nos sea ya posible comenzar la visita de esta dilatada Diócesis, que el Señor, sin ningún mérito de nuestra parte, se ha dignado confiar a Nuestro cuidado, hemos resuelto dar principio a ella en la forma que previenen los sagrados cánones; $y$ como deseamos con el divino auxilio desempeñar este deber de nuestro cargo con la mayor diligencia que nos sea posible. hemos creido necesario hacerlo saber a todos los fieles encomendados a Nuestra solicitud y a cuantos pudiera interesar su noticia. Por lo que les anunciamos que el dia cinco de el próximo mes de diciembre, hemos determinado dar principio a la visita general de la Parroquias, Iglesias, Oratorios, Cofradias, Lugares Pios y Demás que Nos toque, por razón de nuestra jurisdicción y cargo. A cuyo efecto ordenamos a todos los párrocos, capellanes, Mayordomos, Administradores y demás quienes incumba, el que tengan preparados los inventarios de los bienes y alhajas, el catálogo de las reliquias, los líbros, cuentas, razones y demás que sea necesario para la dicha visita. Siendo nuestro deseo el que esta se haga de manera que en cuanto penda de Nosotros, apoyados en el auxilio de la gracia divina, se promueva el culto del Señor, la reforma cristiana de las costumbres de los fieles, el más asiduo trabajo de los Ministros del Señor y todo cuanto pueda conducir al provecho de las almas rescatadas con la sangre preciosa de Nuestro Señor Jesucristo, encargamos a dichos párrocos el que hagan saber a sus feligreses los fines y objetos de la visita episcopal, les instruyan acerca de las obligaciones que con esta vocación han de desempeñar y les preparen a recibir el Santo Sacramento de la Confirmación, que habremos de administrar, manifestandoles que con fílial confianza deben dirigirse a Nos por escrito o de palabra, en todo aquello que crean conducir a la gloria de Dios, a la utilidad de la Iglesia y al bien de las almas. Mandamos a todos los eclesiásticos, beneficiados o no beneficiados, que cuando hubiéremos de visitar la parroquia en que residan, tengan prontos y exhiban los titulos de su beneficio, órdenes o facultades que tuvieren para administrar sacramentos o ejercer otras funciones de su ministerio: y tanto a ellos como a los Capellanes Oficiales, Diputados, Mayordomos o Administradores de las Cofradias y Lugares Pios, el que estén prevenidos para presentar las fundaciones, libros, catálogos de obligaciones de misas, limosnas u otras obras pias, junto con las cuentas de administración y manejo, para ser en debida forma examinados. A todos universalmente ordenamos, bajo pena de nuestro arbitrio, a más de las que dispone el derecho, que hagan ante nos o ante nuestros convisitadores, la denuncia de los que por hecho o palabra sean sospechosos de herejia, excomulgados o que de alguna manera perviertan las costumbres; exhortando y rogando en el señor a todo aquel que tuviere que comunicarnos cualquier asunto, se desnude de toda pasión y mire en lo que hace únicamente a la gloria del Señor. Y para que este nuestro edicto llegue a noticia de todos. mandamos que se promulgue en las Iglesias del Arzobispado en los dias festivos y se fije en los lugares acostumbrados.- Dado en esta ciudad de Santiago a veinte y un dia del mes de noviembre de mil ochocientos cincuenta y tres. RAFAEL VALENTIN, ARZOBISPO DE SANTIAGO., Por mandato de S.S: IIlma. y Rma.Zóilo Villalón, Secretario. 